\title{
Laser cladding of NiCrBSiFe-WC coating with multichannel laser
}

\author{
L. E. Afanasieva ${ }^{\dagger}$, G. V. Ratkevich \\ †ludmila.a@mail.ru \\ Tver State Technical University, 22 A. Nikitin Quay, 22, Tver, 170026, Russia
}

\begin{abstract}
A metalloceramic NiCrBSiFe-WC coating on structural steel $40 \mathrm{Kh}$ was prepared by the method of laser cladding. The cladding was performed using a multichannel continuous $\mathrm{CO}_{2}$ laser radiation using the complex of ALTKU3 model produced by LLC "Centre of laser technologies", the city of Vladimir. The complex includes a multichannel (40 rays) $\mathrm{CO}_{2}$ laser with the output power of $3 \mathrm{~kW}$ and a technological stand with five coordinates for ray manipulation and with two ones for manipulation of the piece under processing. The prepared samples were examined metallographically. It is shown that at optimal modes a practically pore-free coating is formed with a minimal penetration into the base ensuring metallurgical fusion. According to the $\mathrm{X}$-ray spectral microanalysis data the chemical composition is practically the same as that of the raw powder. In particular, the content of iron in the granules and in the matrix is nearly the same (about $4 \ldots .5 \%$ ). Due to the automatization of the processing by crossed rollers the sample surface after cladding is nearly flat and only requires a slight machining. The thickness of the cladding layer is about $700 \mu \mathrm{m}$ in one pass. No cracks in the plane of the sample were observed. The weld junction demonstrates the same structure lengthwise thus indicating a high uniformity of the heat input during the cladding. The size of the thermal effect zone in the substrate is about $450 \mu \mathrm{m}$. The laser cladding of the highly alloyed powder of the system NiCrBSiFe-WC onto the structural steel by means of the multichannel $\mathrm{CO}_{2}$ laser makes it possible to obtain a high-quality wear-proof coating since, in contrast to single ray lasers, it provides a high uniformity of integral heat input in the processing zone.
\end{abstract}

Keywords: multichannel laser, laser cladding, nickel alloy, coating.

УДК: 621.7

\section{Лазерная наплавка покрытия $\mathrm{NiCrBSiFe}-\mathrm{WC}$ с помощью многоканального лазера}

\author{
Афанасьева Л.Е. ${ }^{\dagger}$, Раткевич Г.В. \\ Тверской государственный технический университет, наб. А. Никитина, 22, Тверь, 170026, Россия
}

\begin{abstract}
Методом лазерной наплавки получено металлокерамическое покрытие системы $\mathrm{NiCrBSiFe-WC} \mathrm{на} \mathrm{конструкци-}$ онную сталь марки 40X. Наплавку выполняли с помощью непрерывного излучения многоканального СО 2 лазера на комплексе модели АЛТКУ-3 производства ООО «Центр лазерных технологий», г. Владимир. Комплекс состоит из многоканального (40 лучей) $\mathrm{CO}_{2}$-лазера с мощностью выходного излучения 3 кВт и технологического поста с пятью координатами манипулирования лучом и двумя координатами манипулирования обрабатываемой деталью. Проведены металлографические исследования полученных образцов. Показано, что при выполнении лазерной наплавки на оптимальных режимах формируется практически беспористое покрытие с минимальным проплавлением материала основы, обеспечивающим металлургическое сплавление. По данным рентгеноспектрального микроанализа химический состав наплавленного покрытия практически не отличается от химического состава используемого порошка, в частности, количество железа в гранулах и матрице наплавки близки (около 4...5\%). Поверхность образцов после наплавки перекрывающимися валиками почти плоская, благодаря автоматизации процесса и требует незначительной последующей механической обработки. Толщина наплавленного слоя около 700 мкм $3 а$ один проход. Трещин в плоскости шлифа не обнаружено. Линия сплавления одинакова по строению, что показывает высокую однородность тепловложения при наплавке. Размер зоны термического влияния в материале подложки около 450 мкм. Лазерная наплавка высоколегированной порошковой смеси системы NiCrBSiFe-WC на конструкционную сталь с использованием многоканального $\mathrm{CO}_{2}$ лазера позволяет получать качественные износостойкие покрытия благодаря тому, что данный лазер в отличие от однолучевых, обладает высокой степенью однородности интегрального тепловложения в зоне обработки.
\end{abstract}

Ключевые слова: многоканальный лазер, лазерная наплавка, никелевый сплав, покрытие. 


\section{1. Введение}

Эффективным способом повышения ресурса деталей машин и инструментов является нанесение покрытий с высокими эксплуатационными свойствами $[1,2]$. Покрытия на никелевой основе $\mathrm{NiCrBSi}$ широко используются для повышения износостойкости и коррозионной стойкости, восстановления изношенных поверхностей деталей машин. Благодаря высоким технологическим свойствам и, прежде всего, способности к самофлюсованию, порошки системы $\mathrm{NiCrBSi}$ используют для наплавки и напыления различными способами [1-3]. Резервом повышения износостойкости покрытий является создание на их основе композиций с карбидным или интерметаллидным упрочнением. В работе [3] методом газопорошковой лазерной наплавки получено металлокерамическое покрытие $\mathrm{TiC}-\mathrm{NiCrBSi}$ с повышенной твердостью и абразивной износостойкостью. Авторы статьи [4] порошковую смесь состава $\mathrm{WC}-\mathrm{NiCrBSiFe}$ дополнительно модифицировали наноразмерным порошком $\mathrm{Al}_{2} \mathrm{O}_{3}$ и методом плазменно-порошковой наплавки получили покрытия с улучшенными свойствами.

Анализируя результаты практического использования и многочисленных экспериментальных исследований, авторы ряда публикаций отмечают, что качество износостойких покрытий не всегда удовлетворяет требованиям, предъявляемым для работы в тяжелых условиях эксплуатации. Нередко покрытия содержат поры, не имеют высокой прочности соединения с основой, а также между металлической матрицей и керамической фазой [5-13]. В связи с этим разрабатываются гибридные технологии, позволяющие улучшить свойства износостойких покрытий. Например, после газотермического напыления полученные покрытия рекомендуется переплавлять с помощью лазера [7], оплавлять плазменной струей, дуговой сваркой $[8,9]$, выполнять горячее изостатическое прессование $[10,11]$, термическую обработку и плавление материала покрытия в печи [12]. Гибридные технологии, как правило, формируют улучшенный комплекс свойств: снижается пористость, повышаются твердость, модуль упругости, адгезионная прочность соединения покрытия с основой. Вместе с тем, гибридные технологии усложняют технологический процесс, повышают его стоимость.

Применение технологии порошковой лазерной наплавки позволяет избежать части проблем, возникающих при нанесении износостойких покрытий другими способами. Известно, что лазерная наплавка имеет небольшую зону термического влияния, минимальное перемешивание основного и наплавляемого материала, получение прочной металлургической связи между наплавленным слоем и основой, возможность полной автоматизации $[2,14-17]$. При лазерной наплавке линия сплавления имеет характерный профиль, повторяющий распределение плотности мощности лазерного излучения по сечению дорожки. По мере приближения к поверхности подложки наблюдается частичное перемешивание материала наплавки и подложки. Для формирования наплавленных слоев, равномерных по толщине, с малым коэффициентом перемешивания $(0.05 \ldots 0.15)$ в результате незначительного проплавления основы важную роль играет степень однородности интегрального тепловложения по ширине дорожки. При нанесении покрытий с помощью технологии лазерной наплавки, как и при лазерном термоупрочнении, положительные результаты получены при использовании многоканальных $\mathrm{CO}_{2}$ лазеров [17, 18]. Многоканальные лазеры, в отличие от однолучевых, могут обеспечить более однородное распределение плотности мощности в зоне обработки. Цель настоящей работы - исследовать структуру и свойства металлокерамического покрытия $\mathrm{NiCrBSiFe}-\mathrm{WC}$, полученного с помощью порошковой наплавки многоканальным $\mathrm{CO}_{2}$ лазером.

\section{2. Методы проведения исследований}

Для лазерной наплавки использовали порошковую смесь марки ПС-12НВК-01 (ГОСТ 28377-89). Смесь состоит из 35\% WC - карбида вольфрама и 65\% гранулированного порошка марки ПГ-10Н-01 с химическим составом согласно ТУ 48-19-383-91, \% (масс.): $0.6 \ldots 1.0 \mathrm{C} ; 14 \ldots 20 \mathrm{Cr} ; 2.8 \ldots 4.2 \mathrm{~B} ; 4.0 \ldots 4.5 \mathrm{Si} ; 3.0 \ldots 7.0 \mathrm{Fe}$; ост. - Ni. Материалом подложки служила конструкционная сталь марки 40Х (ГОСТ 4543-71). Для изучения микроструктуры и измерения микротвердости отдельных частиц порошковой смеси были изготовлены шлифы с помощью их заливки эпоксидной смолой с отвердителем, шлифовки, полировки и химического травления путем протирания раствором следующего состава: 20 мл $\mathrm{HCl}, 20$ мл $\mathrm{H}_{2} \mathrm{O}, 4$ г $\mathrm{CuSO}_{4} \times 5 \mathrm{H}_{2} \mathrm{O}$ [19].

Наплавку выполняли с помощью лазерного комплекса модели АЛТКУ-3. Это полностью отечественная разработка производства ООО «Центр лазерных технологий», г. Владимир. Комплекс состоит из многоканального (40 лучей) $\mathrm{CO}_{2}$-лазера с мощностью выходного излучения 3 кВт и технологического поста с пятью координатами манипулирования лучом и двумя координатами манипулирования обрабатываемой деталью. Наплавку проводили непрерывным лазерным излучением на режимах: мощность 2.4 кВт, скорость сканирования 5 мм/с, диаметр пятна на поверхности 6 мм. Присадочный материал предварительно наносили на поверхность основы с помощью специального трафарета, выравнивали по толщине и производили его оплавление лазерным пучком с перекрытием валиков $50 \%$.

Микроструктуру образцов исследовали с помощью растрового электронного микроскопа (РЭМ) JEOL JSM-6610LV и металлографического микроскопа Carl Zeiss Axio Vert.A1MAT. Рентгеноспектральный микроанализ выполняли на энергодисперсионном спектрометре Oxford INCA Energy 350. Микротвердость измеряли на микротвердомере ПМТ-3 вдавливанием алмазного индентора в виде пирамиды согласно ГОСТ Р 8.748-2011 (ИСО 14577-1:2002). 


\section{3. Результаты исследования и их обсуждение}

На Рис. 1. представлено изображение порошковой смеси марки ПС-12НВК-01. Крестиками отмечены участки рентгеноспектрального микроанализа. Химический состав отдельных частиц представлен в Табл. 1.

Как видно из Табл. 1, спектры № $1-3$ соответствуют частицам карбида вольфрама, №4-6 - гранулам никелевого сплава. Частицы карбида вольфрама имеют произвольную форму с грубой, шероховатой поверхностью (Рис. 2), что может снижать сыпучесть порошка и уменьшать его технологические возможности при нанесении композиционных покрытий некоторыми способами. Как отмечается в работе [15], форма частиц карбида вольфрама (сферическая или произвольная) не оказывает заметного влияния на износостойкость покрытий. В то же время существует очевидное преимущество в использовании более крупных частиц размером $750 \ldots 1200$ мкм в жестких условиях эксплуатации, а покрытия с более мелкими частицами (40...160 мкм) улучшают сопротивление износу в условиях скольжения.

Порошок никелевого сплава марки ПГ-10Н-01 получен методом газоструйного распыления расплава, имеет гранулометрический состав, изменяющийся в широких пределах - 25...120 мкм (Рис. 3). На поверхности частиц встречаются сателлиты. Это также может приводить к снижению сыпучести и насыпной плотности порошка.

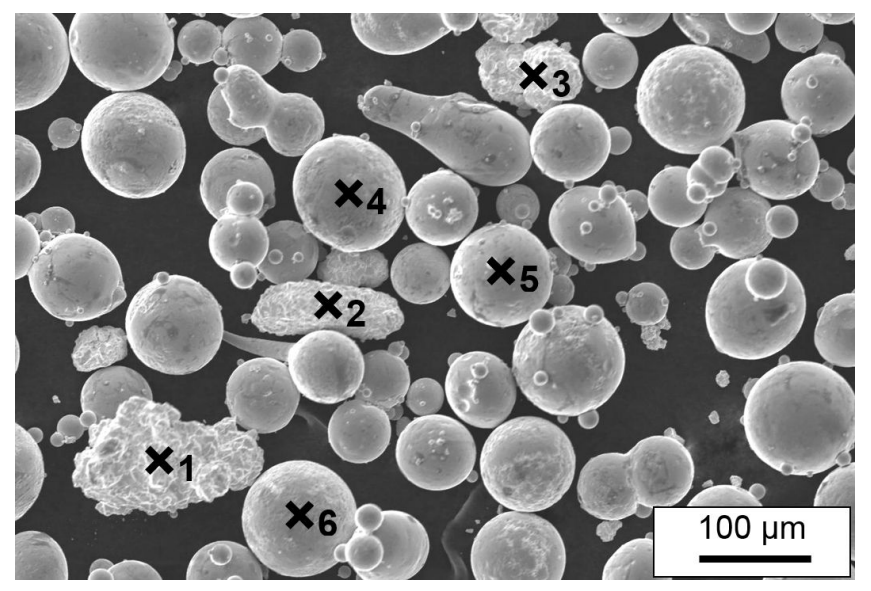

Рис. 1. Изображение порошковой смеси (РЭМ). Крестиками отмечены участки рентгеноспектрального микроанализа.

Fig. 1. SEM image of the powder blend. The crosses refer to X-ray spectral microanalysis areas.

Табл. 1. Химический состав гранул порошковой смеси (масс. \%). Table 1. Chemical composition (mass \%) of blended granules.

\begin{tabular}{|c|c|c|c|c|c|c|c|}
\hline $\begin{array}{c}\text { № } \\
\text { spectrums }\end{array}$ & $\mathrm{C}$ & $\mathrm{W}$ & $\mathrm{Al}$ & $\mathrm{Si}$ & $\mathrm{Cr}$ & $\mathrm{Fe}$ & $\mathrm{Ni}$ \\
\hline 1 & 18.26 & 81.74 & & & & & \\
\hline 2 & 18.11 & 81.89 & & & & & \\
\hline 3 & 16.55 & 83.45 & & & & & \\
\hline 4 & & & 0.51 & 5.62 & 16.59 & 4.17 & 73.11 \\
\hline 5 & & & & 4.98 & 21.43 & 4.0 & 69.59 \\
\hline 6 & & & & 4.99 & 10.06 & 4.83 & 80.11 \\
\hline
\end{tabular}

На Рис. 4 представлено изображение шлифа исследуемой порошковой смеси. Химическое травление выявило микроструктуру гранул никелевого сплава, при этом карбиды вольфрама не протравлены. Это способствует более точной их идентификации. Известно, что при производстве гранул методом газоструйного распыления, капли расплава затвердевают с высокими скоростями $10^{3} \ldots 10^{4} \mathrm{C} / \mathrm{c}[20]$. В результате твердые растворы насыщаются легирующими компонентами, формируется высокодисперсная дендритная структура.

При лазерной наплавке происходит расплавление гранул никелевого сплава, жидкий расплав смачивает частицы карбида вольфрама. В результате последующей высокоскоростной кристаллизации формируется металлокерамическое покрытие. Наплавку необходимо выполнять на оптимальных режимах для обеспечения металлургического соединения наплавленного материала с основой, исключения возможности разбавления покрытия материалом подложки. Армирующие частицы должны равномерно распределяться в объеме покрытия, не опускаться на дно ванны расплава, не растворяться в материале матрицы.

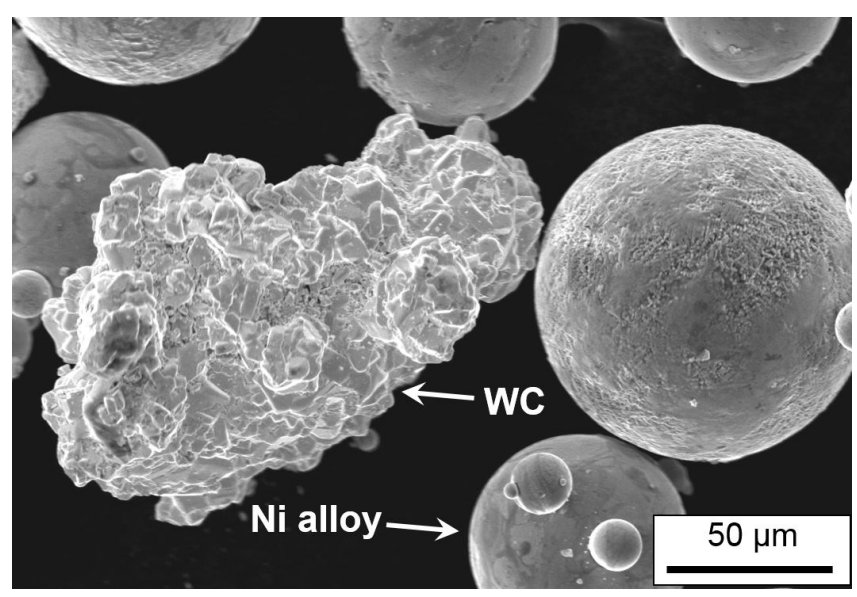

Рис. 2. Изображение морфологии частиц порошковой смеси (РЭМ).

Fig. 2. Morphology of the powder blend as observed by SEM.

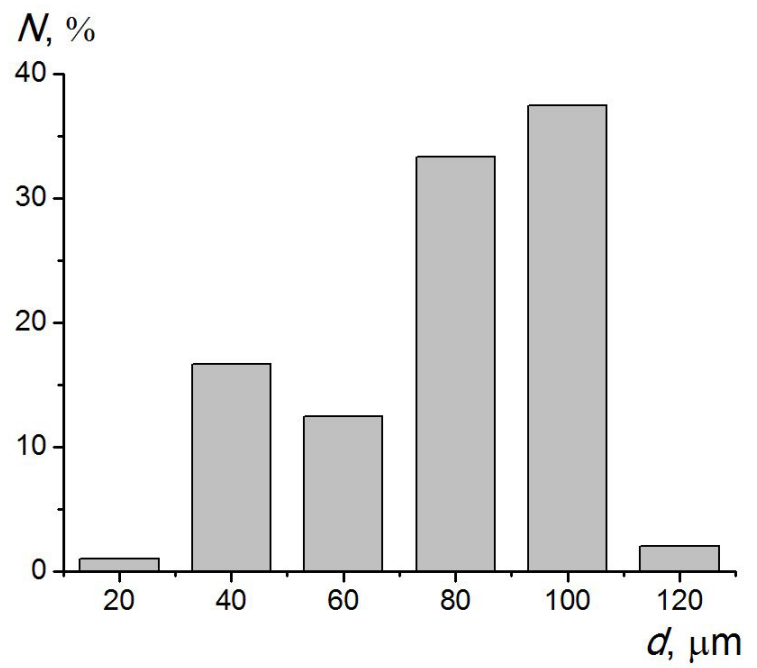

Рис. 3. Распределение частиц порошковой смеси по размеру. Fig. 3. Size distribution of the blended powder. 
Известно, что карбид WC обладает благоприятным сочетанием свойств -высокой твердостью, некоторой пластичностью, хорошей смачиваемостью расплавом. По сравнению с карбидами других переходных металлов WC имеет более высокий модуль упругости, меньший коэффициент термического расширения, обладает стабильностью свойств при нагреве вплоть до $1000^{\circ} \mathrm{C}$ [21]. Высокая плотность энергии при наплавке и длительность термического воздействия могут вызвать значительное растворение карбида WC в матрице, в результа-

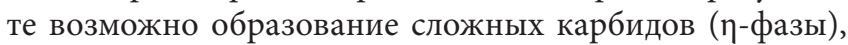
которые существенно охрупчивают покрытие и снижают его эксплуатационные свойства. Если плотности энергии и время воздействия при наплавке недостаточны, то диффузная граница по поверхности карбидов не успеет образоваться, керамика и матрица могут быть плохо связаны.

На Рис. 5 представлено изображение непротравленного шлифа наплавленного покрытия. Поверхность образцов после наплавки перекрывающимися валиками почти плоская благодаря автоматизации процесса и требует незначительной последующей механической обработки. Толщина наплавленного слоя за один проход составляет около 700 мкм. Трещин в плоскости шлифа не обнаружено. Выбранные режимы наплавки

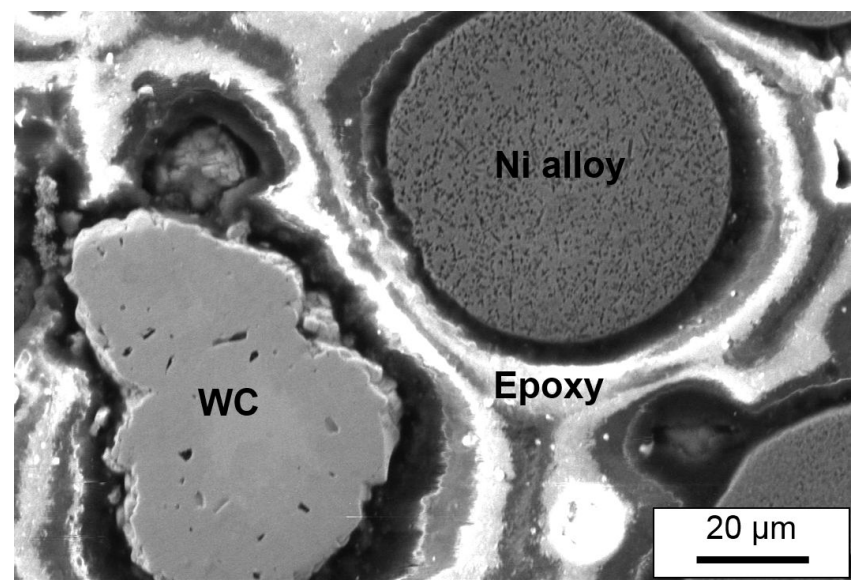

Рис. 4. Изображение шлифа гранул порошковой смеси (РЭМ). Fig. 4. SEM image of the sectioned granules of the blend.

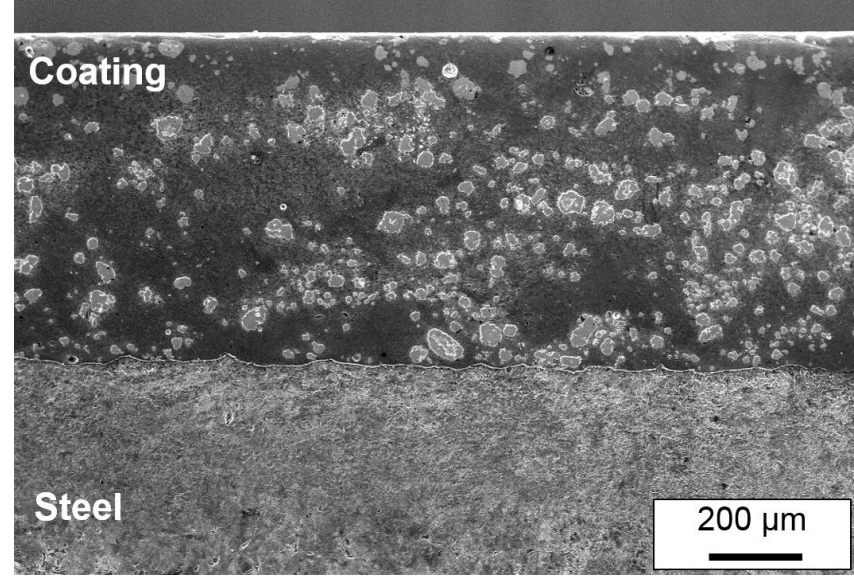

Рис. 5. Изображение шлифа наплавленного покрытия (РЭМ). Fig. 5. Polished section of the fused coating observed by SEM. позволили получить практически беспористое покрытие с минимальным проплавлением материала основы, обеспечивающим металлургическое сплавление. Линия сплавления одинакова по строению, что показывает высокую однородность тепловложения при наплавке. Размер зоны термического влияния в материале подложки составляет около 450 мкм. Распределение частиц карбида вольфрама внутри наплавленного слоя равномерное.

При химическом травлении реактивом Мураками ( 1 часть $20 \%$ водного раствора едкого калия КОН или едкого натра $\mathrm{NaOH}$ и 1 часть $20 \%$ водного раствора красной кровяной соли $\left.\mathrm{K}_{3}\left[\mathrm{Fe}(\mathrm{CN})_{6}\right]\right)$ [19] наличие хрупкой п-фазы не выявлено. Следовательно, при лазерной наплавке на оптимальных режимах не наблюдается заметного растворения карбидов WC в материале матрицы.

На Рис. 6 и 7 представлены электронно-микроскопическое изображение наплавленного покрытия и результаты исследований химического состава материала

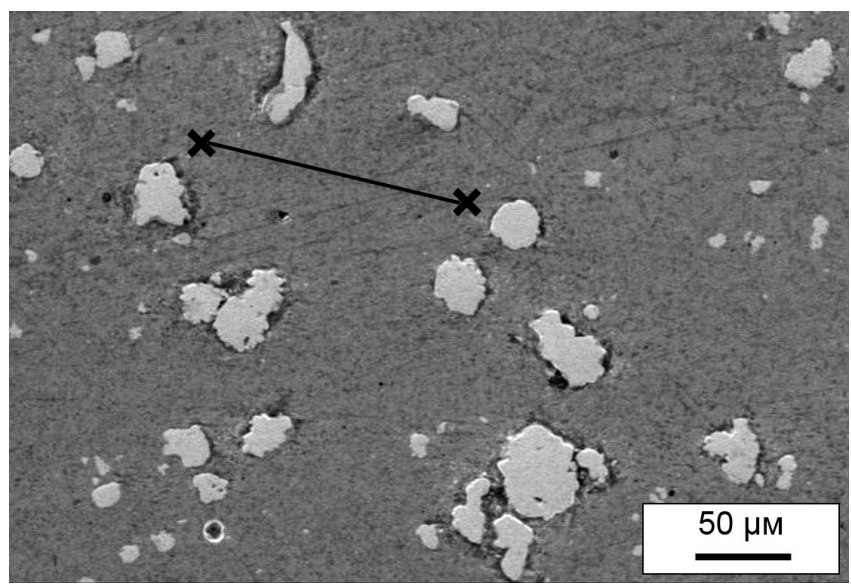

Рис. 6. Изображение наплавленного покрытия (РЭМ). Рентгеноспектральный микроанализ проводили вдоль прочерченной линии.

Fig. 6. Polished micro-section of the fused coating observed by SEM. $\mathrm{X}$-Ray spectral microanalysis was performed along drawn line (SEM).

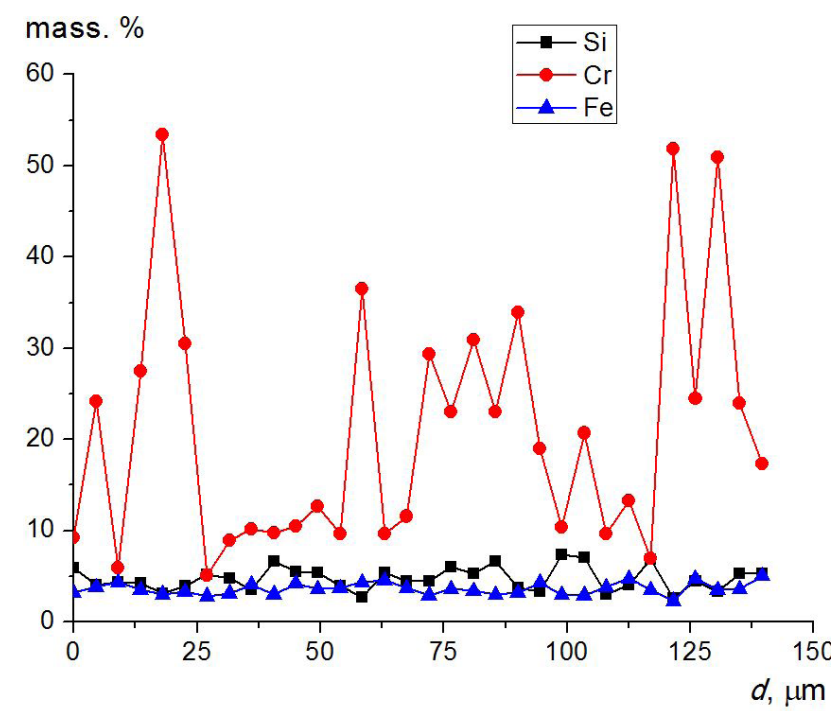

Рис. 7. Распределение химических элементов.

Fig. 7. The distribution of chemical elements. 
матрицы наплавленного покрытия с помощью рентгеноспектрального микроанализа. Набор рентгеновских спектров осуществлялся по 32 точкам с шагом 4.5 мкм вдоль линии, место первой и последней точки отмечены крестиками на электронно-микроскопическом снимке. На Рис. 7 графически показано распределение хрома, кремния и железа на исследуемом участке. Следует отметить, что кремний и железо по сравнению с хромом более равномерно распределяются в материале матрицы. Химический состав наплавленного покрытия практически не отличается от химического состава гранул, в частности, количество железа в гранулах и матрице наплавки близки (около 4...5\%).

На Рис. 8 представлено изображение микроструктуры наплавленного покрытия с отпечатками пирамидального индентора. Результаты измерения микротвердости при усилии 100 г $(0.98$ Н) показаны в Табл. 2. Значения микротвердости карбида WC совпадают с данными других исследователей, в частности [21]. Микротвердость матрицы наплавленного покрытия несколько выше микротвердости используемых для наплавки гранул никелевого сплава. Это можно объяснить, с одной стороны, возможным наличием пор в некоторых гранулах, полученных методом газоструйного распыления расплава, что снижает микротвердость гранул. С другой стороны, при измерении микротвердости матрицы покрытия карбиды WC, расположенные вблизи поверхности шлифа, могут влиять на результат измерения микротвердости в сторону ее увеличения.

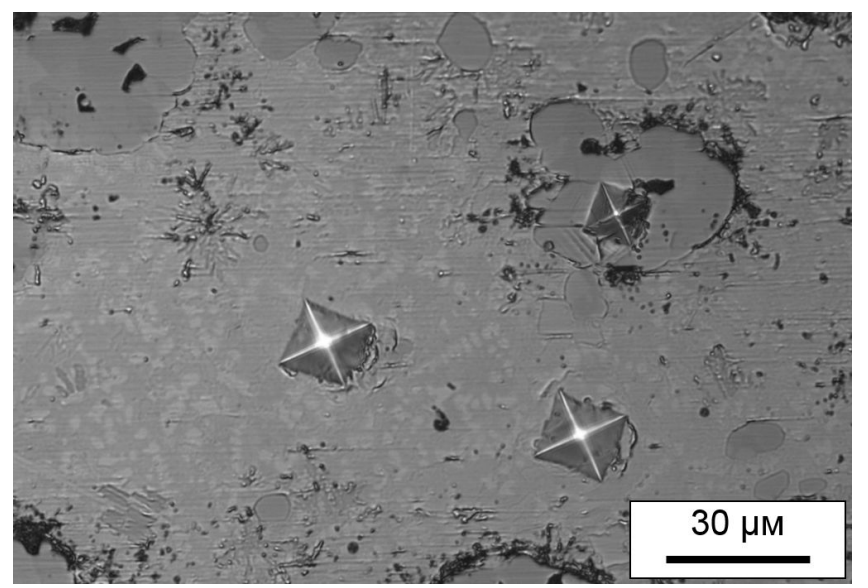

Рис. 8. Микроструктура наплавленного покрытия с отпечатками индентора.

Fig. 8. Microstructure of the fused coating with the prints of the indenter.

Табл. 2. Значения микротвердости, МПа.

Table 2. Microhardness values, MPa.

\begin{tabular}{|c|c|c|}
\hline $\begin{array}{c}\text { Гранулы } \\
\text { Ni сплава } \\
\text { Ni alloy } \\
\text { granules }\end{array}$ & $\begin{array}{c}\text { Частицы WC } \\
\text { WC particles }\end{array}$ & $\begin{array}{c}\text { Матрица металло- } \\
\text { керамического покрытия } \\
\text { Matrix of } \\
\text { metal-ceramic coating }\end{array}$ \\
\hline $7900 \pm 373$ & $20217 \pm 777$ & $9014 \pm 166$ \\
\hline
\end{tabular}

\section{4. Заключение}

Лазерная наплавка высоколегированной порошковой смеси системы $\mathrm{NiCrBSiFe-WC} \mathrm{на} \mathrm{конструкционную}$ сталь с использованием многоканального $\mathrm{CO}_{2}$ лазера позволяет получать качественные износостойкие покрытия благодаря тому, что данный лазер обладает высокой степенью однородности интегрального тепловложения в зоне обработки. Получено беспористое покрытие толщиной 700 мкм за один проход с минимальным проплавлением материала основы, обеспечивающим металлургическое сплавление. Трещин, несплавлений не выявлено. Химический состав покрытия практически не отличается от химического состава используемой для наплавки порошковой смеси, в частности, количество железа в порошке никелевого сплава и матрице наплавки близки (4...5\%).

Благодарности/Acknowledgements. Металлографические исследования выполнены с использованием оборудования регионального центра коллективного пользования на базе Тверского государственного университета./The metallographic studies were performed making use of the equipment of the Regional Center for collective use of Tver State University.

\section{Литература/References}

1. A. Khasui, O. Morigaki. Naplavka i napyleniye (eds. V.S. Stepina, N.G. Shesterkina). Moscow, Mashinostroyeniye (1985) 240 p. (in Russian) [А. Хасуи, О. Моригаки. Наплавка и напыление (ред. В.С. Степина, Н.Г. Шестеркина). Москва, Машиностроение (1985) 240 с.]

2. A.G. Grigor'yants, I.N. Shiganov, A.I. Misyurov. Tekhnologicheskiye protsessy lazernoy obrabotki. Moscow, MGTU (2006) 663 p. (in Russian) [А.Г. Григорьянц, И.Н. Шиганов, А.И. Мисюров. Технологические процессы лазерной обработки. Москва, МГТУ (2006) 663 с.]

3. R.A. Savray, A.V. Makarov, N.N. Soboleva, I. Yu. Malygina, A.L. Osintseva. Obrabotka metallov (tekhnologiya, oborudovaniye, instrumenty). 4, 43 (2014). (in Russian) [Р.А. Саврай, А.В. Макаров, Н.Н. Соболева, И.Ю. Малыгина, А.Л. Осинцева. Обработка металлов (технология, оборудование, инструменты). 4, 43 (2014).]

4. A.N. Smirnov, E. V. Kozlov, M.V. Radchenko, K. V. Knyaz'kov, V.L. Knyaz'kov. Izv. vuzov. Chernaya metallurgiya. 59(4), $245 \quad$ (2016). (in Russian) [А.Н. Смирнов, Э.В. Козлов, М.В. Радченко, К.В. Князьков, В.Л. Князьков. Изв. вузов. Черная металлургия. 59(4), 245 (2016).] DOI: 10.17073/0368-0797-2016-4-245-250

5. A. Martın, J. Rodriguez, J.E. Fernandez, R. Vijande. Wear. 251(1-12), 1017 (2001). DOI: 10.1016/S0043-1648(01)00703-7

6. S. Stewart, R. Ahmed, T. Itsukaichi. Wear. 257(9-10), 962 
(2004). DOI: 10.1016/j.wear.2004.05.008

7. N. Serres, F. Hlawka, S. Costil, C. Langlade, F. Machi. J. Therm Spray Tech. 20(1-2), 336 (2011). DOI: $10.1007 /$ s11666-010-9565-1

8. A.D. Pogrebnyak, S.N. Bratushka, M.V. Il'yashenko et al. J. Frict. Wear 32, 84 (2011). DOI: $10.3103 / \mathrm{S} 1068366611020085$

9. B.M. Dhakar, D.K. Dwivedi, S.P. Sharma. Surface Engineering. 28(1), 73 (2012). DOI: 10.1179/1743294411Y.0000000051

10. S. Stewart, R. Ahmed, T. Itsukaichi. Surface and Coatings Technology. 190(2-3), 171 (2005). DOI: 10.1016/j.surfcoat.2004.04.059

11. V. Stoica, R. Ahmed, T. Itsukaichi, S. Tobe. Wear. 257(11), 1103 (2004). DOI: 10.1016/j.wear.2004.07.016

12. Z. Bergant, J. Grum. Journal of thermal spray technology. 18(3), 380 (2009). DOI: 10.1007/s11666-009-9304-7

13. O.V. D’yachenko. Nauka i tekhnika. 2, 13 (2014). (in Belarusian) [О.В. Дьяченко. Наука и техника. 2, 13 (2014).]

14. M.J. Tobar, C. Alvarez, J.M. Amado, G. Rodríguez, A. Yáñez. Surface and Coatings Technology. 200(22-23), 6313 (2006). DOI: 10.1016/j.surfcoat.2005.11.093

15. D. Deschuyteneer, F. Petit, M. Gonon, F. Cambier. Surface and Coatings Technology. 311, 365 (2017). DOI: $10.1016 /$ j.surfcoat.2016.12.110

16. J. Przybyłowicz, J. Kusiński. Journal of Materials
Processing Technology. 109(1-2), $154 \quad$ (2001). DOI: 10.1016/S0924-0136(00)00790-1

17. V.I. Yugov, L. Ye. Afanasieva, M. V. Novoselova. Uprochnyayushchiye tekhnologii i pokrytiya. 11, 19 (2016). (in Russian) [Югов В.И., Афанасьева Л.Е., Новоселова М.В. Упрочняющие технологии и покрытия. 11, 19 (2016).]

18. V.I. Yugov, L.E. Afanasieva, I. A. Barabonova, G.V. Ratkevich. Letters on materials. 7(1), 8 (2017). (in Russian) [В.И. Югов, Л.Е. Афанасьева, И. А. Барабонова, Г. В. Раткевич. Письма о материалах. 7(1), 8 (2017).] DOI: 10.22226/2410-3535-2017-1-8-11

19. M. Bekkert, Kh. Klemm. Sposoby metallograficheskogo travleniya: Sprav. izd. Moscow, Metallurgiya (1988) 400 p. (in Russian) [M. Беккерт, Х. Клемм. Способы металлографического травления: Справ. изд. Москва, Металлургия (1988) 400 c.]

20. A. F. Belov, N.F. Anoshkin, O. Kh. Fatkullin. Struktura i svoystva granuliruyemykh nikelevykh splavov. Moscow, Metallurgiya (1984) 128 p. (in Russian) [А.Ф. Белов, Н.Ф. Аношкин, О.Х. Фаткуллин. Структура и свойства гранулируемых никелевых сплавов. Москва, Металлургия (1984) 128 с.]

21. A.S. Kurlov, A.I. Gusev. Russian Chemical Reviews. 75(7), 617 (2006). (in Russian) [Курлов A.C., Гусев А.И. Успехи химии. 75(7), 687 (2006).] DOI: 10.1070/RC2006v075n07ABEH003606 